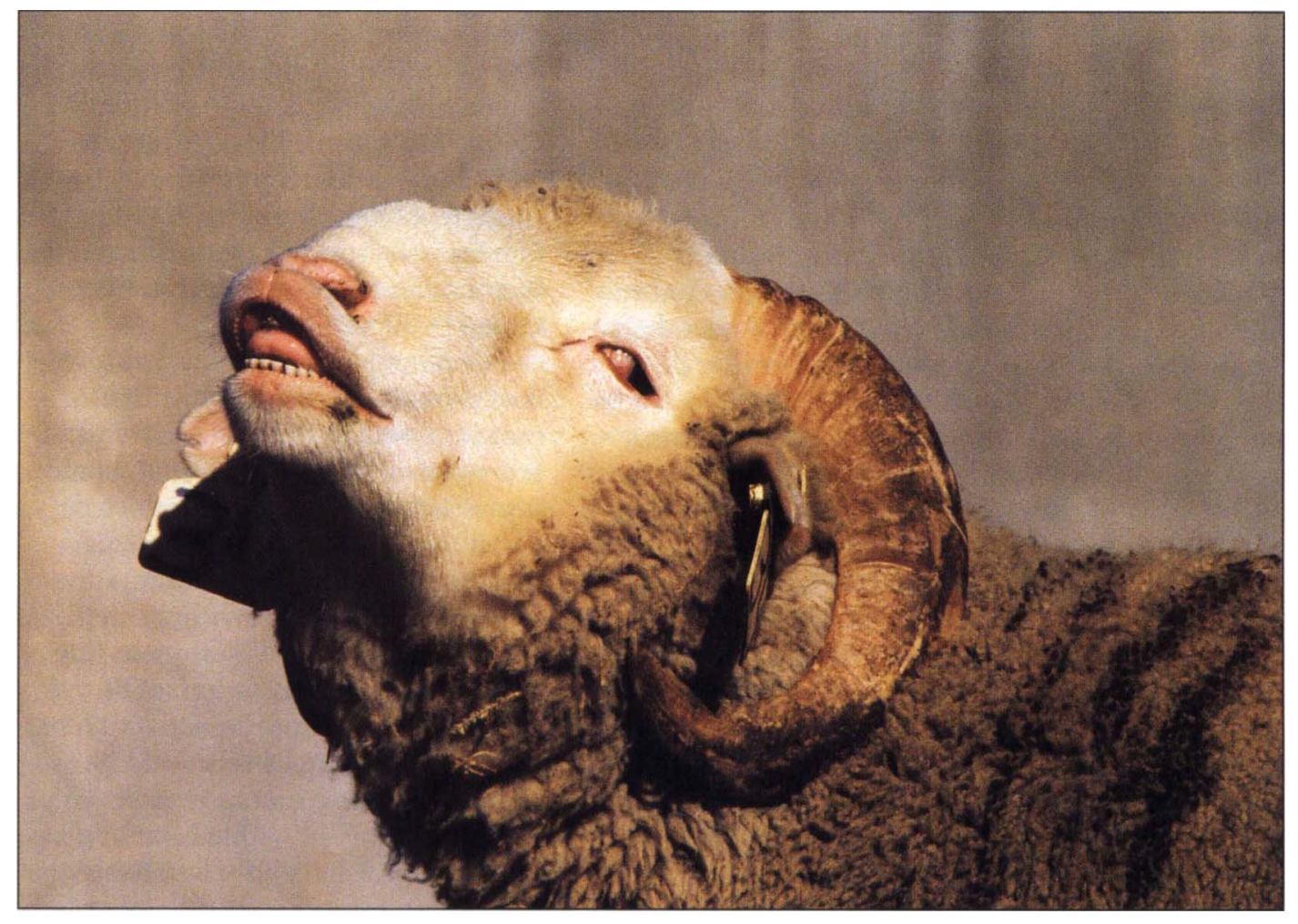

A ram responds to olfactory stimuli from an estrous ewe by exhibiting the Flehman response. Ram lambs exposed to ewes shortly after puberty (8-9 months of age) attained more successful matings as yearlings than rams that were 20 months old when first exposed to estrous ewes.

\title{
Early sexual experience improves ram breeding
}

\author{
Edward O. Price $\square \quad$ Martin R. Dally $\square \quad$ Reid Borgwardt
}

\begin{abstract}
Research on the development of sexual behavior in male sheep has demonstrated that ram lambs are sufficiently mature in their first year of life to assume an important role in sheep-breeding programs. Lack of sexual experience in the first year can result in sexual inactivity, reduced mating rates, and abnormal sexual orientation in the yearling year. Variability in rams' sexual performance can be evaluated by simple mating tests administered prior to the breeding season. The greater reproductive success of highperforming rams is achieved not only by a higher rate of mating but also by a tendency to distribute matings over more females. High libido rams are not inherently more aggressive.
\end{abstract}

Sheep producers welcome new ideas to improve the efficiency of their sheep breeding programs. Our research on the sexual behavior of male sheep at UC Davis and the UC Hopland Research and Extension Center is designed to provide new insights into the reproductive management of rams by investigating: (1) the development of sexual behavior; (2) methods of evaluating sexual performance; and (3) other traits that may influence sexual performance.

\section{Development of sexual behavior}

In California, most ram lambs are weaned at about 3 months of age and isolated from females until they are used for breeding at approximately 18 to 20 months. Most sheep producers consider ram lambs too immature to be very useful in their breeding programs. Our research has demonstrated that ram lambs are sufficiently mature in their first year of life to assume an important role in sheep breeding programs. We also have demonstrated that isolation of males from females during the first year of life can be detrimental to their subsequent sexual performance.

Ram lambs from the UC Hopland Research and Extension Center flock (commercial Targhee strain) typically reach puberty at about 6 to 8 months of age. When 175 ram lambs were first exposed to sexually receptive (estrous) ewes for 30 minutes at 6 months of age, approximately $30 \%$ exhibited successful matings (ejaculations), also referred to as services. This percentage doubled to $60 \%$ with three additional exposures to estrous ewes at weekly intervals. When 26 ram lambs were first exposed to estrous females at 8 months of age, 11 of them, or $42 \%$, 
attained successful matings. At the second exposure, 22 , or $85 \%$, of these rams serviced females, and after four weekly 30-minute sessions (at about 9 months of age) the entire population of males had successfully mated with females.

Early sexual experience can have important effects on adult sexual performance. When rams were exposed to estrous females for the first time at 20 to 21 months of age, 13 of 47 animals ( $28 \%$ ) investigated (i.e., sniffed), but otherwise showed no interest in females in 30-minute sexual performance tests. In contrast, only 1 of 48 rams was sexually inactive at 20 months of age if given four 30-minute exposures to estrous females at 8 to 9 months of age. By the fourth week of testing, the number of sexually inactive 20-to-21-month-old rams, from the former "inexperienced" population, was reduced from 13 to 7 . Not only were there group differences in the proportion of rams that displayed sexual inactivity, but important differences were also found in levels of sexual performance of rams that were sexually active. Number of ejaculations per 30-minute test was approximately $25 \%$ higher for the rams given early heterosexual experience (table 1 ).

Ten additional tests were conducted on the seven sexually inexperienced animals that were still sexually inactive at the end of the fourth week of testing. Six of the seven rams eventually mated with females, but only after week-long exposures to ewes. Once they started mating, the mean ejaculation rate of these six rams was about the same as the rest of the population. The seventh ram in this group was male-oriented; he would court and mount only males.
In nearly every case, a small percentage ( 1 to $5 \%$ ) of rams in our studies demonstrated male sexual orientation. Sexual orientation can be determined by presenting rams with a choice of restrained males and females. Some ram lambs prefer to mount males at first but after continuous exposure to females change their preference. The sexual preference of other male-oriented rams could not be reversed by month-long continuous housing with females. Furthermore, rearing males with females does not guarantee that they will develop a sexual preference for females. In a study of 24 rams reared continuously with females from birth to 10 months of age, two became male-oriented. A preliminary study has shown no support for a genetic basis of sexual orientation. The sons of male-oriented rams conceived through artificial insemination were no more likely to develop male sexual orientation than the sons of female-oriented rams.

\section{Evaluating sexual performance}

Rams are highly variable in their sexual performance. Some of this variation may be due to sexual libido or motivation and some to mating technique. All of these factors may be influenced by genetics and experience. Because of this variability, sheep producers should determine the relative mating potential of flock sires before introducing them to ewes. This can be accomplished by conducting simple sexual performance tests. A typical test is to place individual rams with three or four estrous ewes in a relatively small enclosure for a specified period of time. If the objective is simply to determine whether a male is sexually active and exhibits proper

TABLE 1. Mean number of ejaculations attained by sexually active, experienced and inexperienced rams per weekly 30 -minute exposure to 4 sexually receptive females

\begin{tabular}{lllll}
\hline \hline & \multicolumn{4}{c}{ Test (week) } \\
\cline { 2 - 5 } & 1 & 2 & 3 & 4 \\
Sexually experienced rams $(\mathrm{N}=48)$ & 3.6 & 3.8 & 4.3 & 4.1 \\
Sexually inexperienced rams $(\mathrm{N}=47)$ & 2.6 & 3.2 & 3.4 & 3.4 \\
\hline Sexually experienced rams exhibited significantly greater $(\mathrm{P}<0.001)$ & ejaculation rates than sexually active \\
inexperienced rams.
\end{tabular}

mounting technique, the test could end with the first successful mating. If the objective is to compare different ejaculation rates, a longer observation period is required. For example, one could record the time required to attain two services or one could monitor the number of services each ram attained in 30 minutes.

Sexual performance tests are also useful in identifying rams with locomotor or anatomical defects. Rams often mount repeatedly without gaining intromission (proper insertion of penis) if they have structural defects such as hind limbs that cannot fully support their weight when mounting. Many structural problems including genital abnormalities may not be evident until the animal is seen mounting. In general, animals should be culled that fail to mount females, mount repeatedly without gaining intromission, or have relatively low ejaculation rates. Rams with low ejaculation rates may be used in breeding programs, but a higher ram-to-ewe ratio is then required.

The mode of estrous induction used to prepare ewes for sexual performance tests is not important. Rams do not respond differently to spayed females induced to exhibit estrus by hormone treatment (progesterone followed by estrogen), than to unspayed females either cycling naturally or induced to exhibit estrus using vaginal sponges treated with progesterone. Unrestrained estrous ewes should be used as stimulus females whenever possible. Most restrained non-estrous ewes do not stand well enough when mounted to provide reliable test results; ejaculation rates are typically underestimated. When using unrestrained estrous ewes, it is important to remove non-estrous females from the group. In small arenas, some rams will choose to pursue non-estrous females for a short time rather than attend to sexually receptive ewes, perhaps because a moving ewe attracts their attention more than one that is standing immobile.

Some concern has been expressed that sexual performance tests may spread sexually transmitted diseases. One way to minimize this is to cover 
the ewe's anogenital region with cloth or put an apron on the ram to prevent intromission. Under normal mating conditions, each ejaculation is followed by a short refractory period of sexual inactivity during which no mounting occurs. Rams unable to intromit because of the cloth barrier do not experience these refractory periods and will mount about five times as frequently during a 30-minute period as rams that can copulate. Mounting frequency under these circumstances correlates fairly well with ejaculation frequency in the absence of the cloth barrier $(r=0.70)$. Another approach is to place the stimulus females in a small wire pen within the test arena. Of course, this precludes mounting, but the frequency of courtship behaviors directed at the female under these conditions correlates significantly with ejaculation rate $(r=0.66)$. However, while relative frequencies of mounting and courtship behaviors under these artificial circumstances provide some indication of the ram's interest in females, such tests do not provide any assurance the male can complete a successful mating.

Barnyard sexual performance scores predict breeding success when rams are exposed to relatively large numbers of estrous-synchronized ewes. In a study conducted at the USDA Sheep Experiment Station in Dubois, Idaho, by Ann Perkins and Jim Fitzgerald, the reproductive suc-

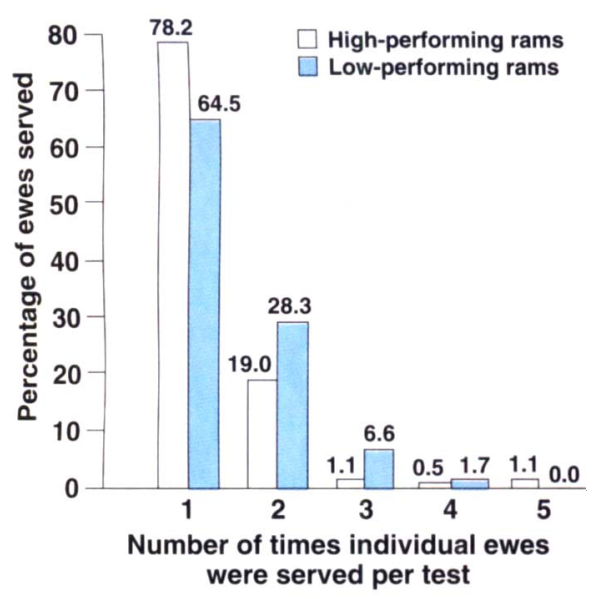

Fig. 1. Percentage of ewes that received one to five services by individual rams exhibiting high and low levels of sexual performance. cess of four high-performing and four low-performing rams was compared when each male was exposed to about 30 estrous-synchronized females for 9 days in a 35-foot-by-40-foot outdoor enclosure. Prior to testing, highperforming rams had attained a minimum of six ejaculations in $\mathbf{3 0}$ minutes, and low-performing rams had attained a maximum of two ejaculations in that same period of time. The four highperforming rams mounted three times more ewes than the four low-performing rams during the 9-day test period (means $=97 \%$ vs. $32 \%$, respectively). Ewes exposed to the high- performing rams were 2.5 times more likely to lamb than ewes exposed to low-performing rams (means $=90 \%$ vs. $36 \%$, respectively). Consequently, the mean number of lambs born per ewe exposed (to rams) was 2.4 times greater for ewes exposed to high- performing rams (1.85 vs. 0.78 lambs, respectively). The number of lambs born per ewe lambing did not differ.

The greater reproductive success of high-performing rams is achieved not only by a higher rate of ejaculation but also by a tendency to distribute matings over more females. In a recent study, 13 high-performing and 11 lowperforming rams were individually exposed to 10 estrous ewes in a small pen for 30 minutes on three occasions. Trials were terminated once the rams had achieved six ejaculations. The high- and low-performing rams averaged 29 and 77 minutes, respectively, to attain the required six ejaculations. The two groups of rams investigated and courted an equal number of ewes. However, the high-performing rams copulated fewer times with each individual ewe than did low-performing males (fig. 1). As a result, highperforming rams mated with a greater number of ewes than did low-performing males (4.7 vs. 4.2 ewes per test, respectively). Femaleto-male ratios of 75:1 are justified with such high-performing males.

Attempts to predict adult sexual performance or sexual orientation by observing male-male mounting in allmale groups have been unsuccessful. Some high-performing rams (in heterosexual encounters) exhibit little or no male-male mounting in all-male groups. Some rams that readily mount other males in all-male groups will consistently mount females and ignore males when given a choice between the two sexes. Although the circumference of the scrotal sac (i.e., testes size) can be used to estimate sperm production, our research shows that scrotal circumference does not predict sexual performance in sexually mature rams.

The ejaculation rate of male goats and bulls increases by about $75 \%$ when they are given the opportunity to observe other males mounting females immediately prior to being exposed to estrous females themselves. In contrast, sexually experienced rams are not sexually stimulated by such visual cues. Neither do rams show enhanced ejaculation rates after being allowed to contact and sniff the anogenital region of estrous ewes prior to sexual performance tests.

\section{Influence of aggressive behavior}

It is well-known that dominant rams intimidate subordinate males when competing for females. Two experiments were conducted to determine if there was a relationship between levels of sexual performance and aggressive behaviors. Ten highperforming and 10 low-performing rams were selected from a population of 95 males. The rams were about 22 months of age and similar in body weight at the start of testing.

In the first experiment, the 10 highperforming rams were paired with each of the 10 low-performing rams on three occasions in round-robin competition for access to a restrained estrous female. As expected, the high-performing rams attained more mounts and spent more time with the ewe during the 5-minute test periods.

In the second experiment, the rams competed for feed after about 17 hours of food deprivation, using the same pair combinations as described for the first experiment. A bucket containing feed was placed in one corner of the test arena so that only one animal could feed at a time. Mean scores for the different pair combinations revealed no difference in the number of high- and low-performing rams that 


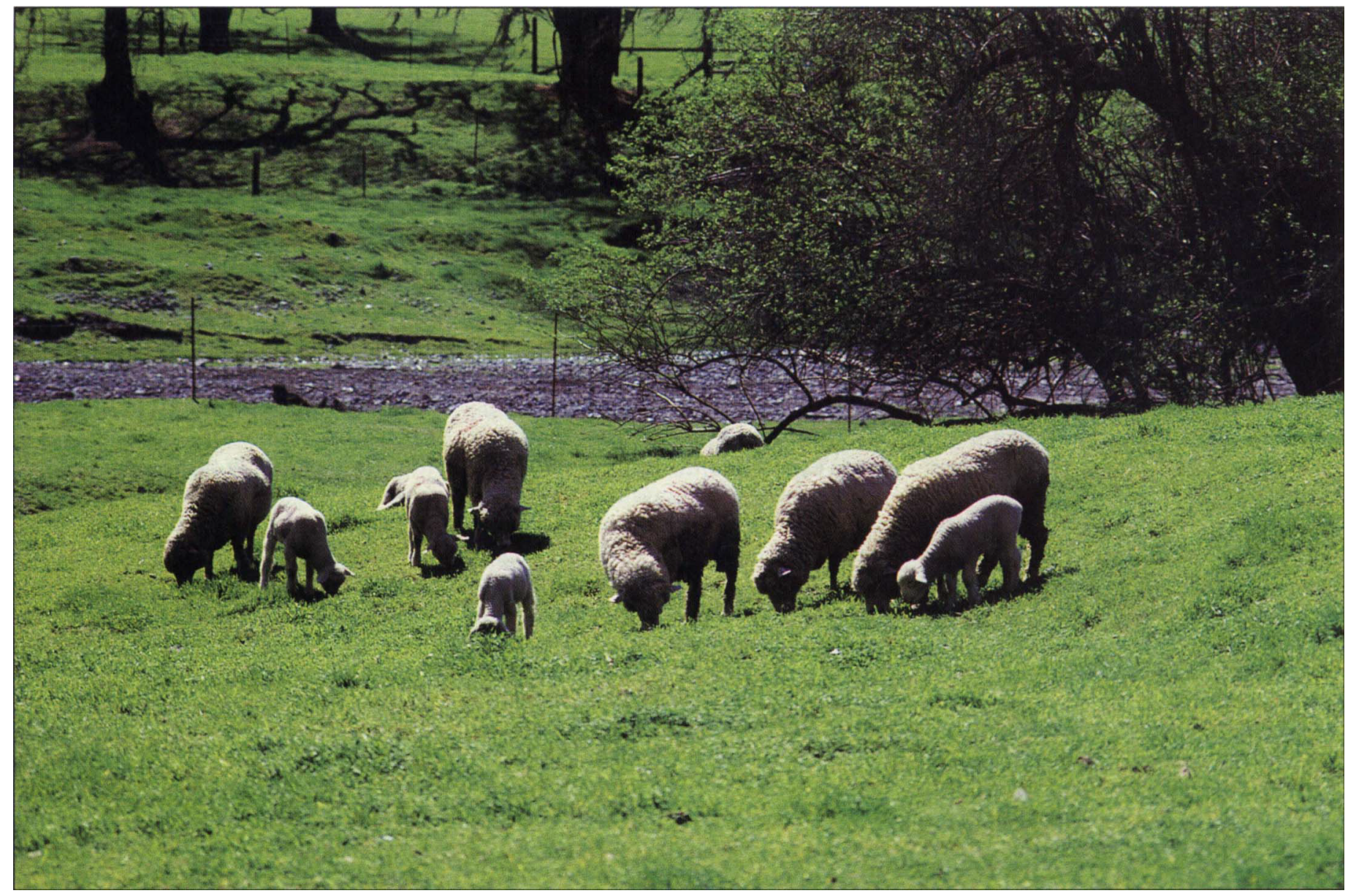

\section{Ewes with lambs. Ewes exposed to high-performing rams were 2.5 times more likely to lamb than ewes exposed to low-performing rams.}

out-competed their partner. Neither group was more aggressive than the other in this context.

Our research demonstrates that considerable variation exists in the sexual performance of male sheep. Individual differences may reflect opportunity to engage in early sexual experience and differences in libido and mating techniques. Sexual performance tests are useful in identifying males that will breed ewes most efficiently both as ram lambs and adults. Unfortunately, other traits that predict sexual performance have not been identified. Attempts to sexually stimulate males using visual and olfactory cues have not been successful.
E. Price is Professor and Chair, M. Dally and $R$. Borgwardt are Staff Research Associates, Department of Animal Science, UC Davis.

The authors would like to acknowledge the assistance of J. Hays and G. Dow in the care and handling of the animals used in this research.

\section{CALIFORNIA AGRICULTURE ASSOCIATE EDITORS}

Animal, Avian, Aquaculture

\& Veterinary Sciences

Christopher M. Dewees

Kathryn Radke

Bennie I. Osburn

Barbara A. Reed

Economics \& Public Pollcy

Harold O. Carter

Alvin Sokolow

\section{Food \& Nutrition}

Barbara Schneeman

Eunice Williamson
Human \& Community

Development

Linda M. Manton

Karen P. Varcoe

Land, Air \& Water Sciences

Pam Matson

Garrison Sposito

Henry J. Vaux, Jr.

Natural Resources

Barbara H. Allen-Diaz

Daniel W. Anderson

Richard B. Standiford
Pest Management

Edward G. Platzer

Joseph G. Hancock, Jr

Michael K. Rust

Frank G. Zalom

\section{Plant Sciences}

Jodie S. Holt

Lee F. Jackson

G. Steven Sibbett http://www.ucop.edu/anrhome/danr.html

Lorrie.Mandoriao@ucop.edu

$\mathrm{PH}$ : (510) 987-0044

FAX: (510) 465-2659 